\title{
The Postdigital Learning Spaces of Higher Education
}

\author{
James Lamb ${ }^{1}$ - Lucila Carvalho ${ }^{2} \cdot$ Michael Gallagher $^{1} \cdot$ Jeremy Knox ${ }^{1}$
}

Accepted: 23 November 2021 /Published online: 1 December 2021

(c) The Author(s), under exclusive licence to Springer Nature Switzerland AG 2021, corrected publication 2022

\section{Introduction}

It has never been more important for those of us with an interest in education to be critically exploring the complex and changing nature of university learning spaces. The last two decades have seen the steady proliferation of digital resources across education and society, resulting in a gradual decentring of the physical classroom, as teachers and students have increasingly become able to negotiate learning spaces beyond the bricks-and-mortar campus (Bayne et al. 2013; Carvalho et al. 2016). This has been accompanied and facilitated by new pedagogies that draw on the potentialities of technology, the flow of data, and the massive amount of academic material that can be accessed online. Most recently, the reconceptualization and redesign of learning spaces and practices has been accelerated and foregrounded by the imposed conditions of Covid-19 (Hodges et al. 2020; Jandrić et al. 2020; Rapanta et al. 2021), as the inaccessibility of the physical campus heightened the strategic importance of digital platforms and pedagogies that enabled universities to remain open while campuses closed. This Special Issue offers a timely and important exploration of the evolving relationship between digital technologies and the learning spaces of higher education.

A starting point for the conversations that follow is that digital technologies are more than a medium for communicating academic material, or that they simply exist as networked containers of educational activity. The laptop computer and learning management system, and the smartphone and software application, are woven into the fabric of the university, shaping its educational spaces and practices. When students and teachers gather for a class, they are present in multiple spaces where the

James Lamb

james.lamb@ed.ac.uk

Lucila Carvalho

L.Carvalho@massey.ac.nz

Michael Gallagher

Michael.S.Gallagher@ed.ac.uk

Jeremy Knox

jeremy.knox@ed.ac.uk

1 University of Edinburgh, Edinburgh, UK

2 Massey University, Palmerston North, New Zealand 
digital, material, biological and social are intrinsically connected and co-determining (Jandrić et al. 2018; Carvalho et al. 2016). Digital technologies shape, and are shaped by, learning spaces and practices.

There is also a need for nuance in how we approach the concept of the learning space, a term which accommodates a range of interpretations across the research literature, as well as in the everyday conversations that take place around and within universities. From the outset, our intention was to welcome different understandings and applications of 'learning space' in the postdigital context of higher education. We see a strength of this Special Issue as being in the different conceptualisations of space, which include the physical classroom and the online platform, but connected also to the practices performed in these settings, and the philosophies that might help us to understand what a learning space is and might be. The productive compatibility of these different interpretations is discussed below.

Among the contributors to this Special Issue are Jos Boys, Peter Goodyear and Lesley Gourlay, whose work has done a great deal to establish higher education learning space as a site of critical examination. However, in a field of study that continues to evolve and expand, we are enthusiastic in welcoming the contribution of newer voices, who bring original approaches and insights into how we might explore those environments where educational activity is performed. These include individual contributions by Kati Fargo Ahern, Jenny Green, Magda Pischetola, Annelies Raes, and Stephanie Wilson, as well as a co-authored article by Dewa Wardak, Carmen Vallis and Peter Bryant. Brought together, the different articles offer a combination of empirical studies and theoretical reflections that help us to better understand the learning spaces of higher education, and how they are being shaped by digital technologies.

\section{Conceptual Space}

As the research literature attests, the idea of a 'learning space' accommodates a wide variety of interpretations. This includes the lecture theatres, libraries and laboratories that have for centuries been the places where scholars have assembled in the pursuit of knowledge and enlightenment. More recently, the contemporary redesign of university campuses has seen corridors and comparable spaces adapted to encourage ad hoc opportunities for learning (Coulson et al. 2015), while canteens have been rethought and rebranded into 'learning cafes' (Boys 2011: 5) where students can log into the course site, check email and download readings between classes.

Not that learning is restricted to the university's real estate. The portability of the computer, combined with the wealth of academic material available online, means that students and teachers are increasingly able to compose work and to converse while situated in ostensibly domestic and social settings beyond the physical campus (Gourlay and Oliver 2018). The online platforms where students and tutors congregate or connect with the university, represent in themselves another conceptualisation of learning space, while the educational practices they engender have provided further lines of critical inquiry. 
It is also possible to interrogate learning space, including its relationship with technology, from a more philosophical position. Bourdieu's concept of 'habitus' (1977), Lefebvre's advancement of the 'spatial triad' (1991), Latour's work around material-semiotics (2005) and Massey's notion of spatial interrelations (2005), alongside other mobilities, spatial and sociomaterial theories, have all shaped research that has sought to recognise the complexity of our educational surroundings. These philosophical takes on learning space enable us to see the classroom as more than physical, or defined simply by the pedagogies that are performed in these settings.

Our openness to the interpretation of learning space within this Special Issue has been rewarded with articles that explore the relationship between educational environments and technologies through questions around accessibility and inequality (Boys 2021), engagement and presence (Raes 2021), the blurring of spatial boundaries (Wardak et al. 2021), pedagogical innovation (Green 2021; Pischetola 2021; Wilson 2021) and soundscaping (Ahern 2021), as well as more overtly theoretical approaches to how we think about educational environments and their practices (Goodyear 2021; Gourlay 2021).

For Gourlay (2021), the popularity of the 'learning space' term within education discourse might be explained by the way it suggests a sense of creativity and of being student-focused, thus capturing two of the more sought-after qualities of contemporary learning design. Looking beyond the immediate attractiveness of the term, however, Gourlay sees the common notion of learning space to be ideologically circumscribed by social constructivism in a way that fails to adequately attend to the wide range of non-human actors that shape educational activity and environments. In response, she draws on social topology, and in particular Law and Mol's (2001) work in Science and Technology Studies on the concept of fire space, to argue that shifting the theorisation of space away from learning enables a more detailed understanding of the flickering and ephemeral and uncanny nature of postdigital education. As online video conferencing platforms like Zoom increasingly become a feature of postdigital higher education, there is an urgent need, Gourlay (2021) argues, to recognise and respond to issues around embodiment, connectedness and inclusion that when left unattended contribute towards alienating encounters in these environments.

Like Gourlay (2021), Wardak et al. (2021) recognise the need to look beyond human interests and concerns when conceptualising space, as they draw on Actor Network Theory to elucidate the complex interaction of digital and non-digital entities that construct educational environments. Sociomaterial perspectives also inform the discussions of learning space, and its relationship with digital technologies, in the studies presented by Boys (2021), Goodyear (2021) and Pischetola (2021). A sociomaterial sensibility discourages us from conceptually reducing a learning space to its physical dimensions and contents, or to immediately overemphasise teaching and learning practices. Instead, we are able to recognise a learning space as contingent on a complex and shifting assemblage of human and non-human actors, which extends beyond the immediate concerns of pedagogy to include, among other things, university strategy, government policy, commercialisation and, as the articles here demonstrate, technology. 
It may be popular to privilege human interests and actions in the design of learning spaces and practices; however, as Goodyear (2021) argues, a positive learning environment does not naturally emerge through carefully planned pedagogy, but can instead benefit from sociomaterial perspectives that are exposed through the likes of ethnographic observation and interviews. As the contributions across this Special Issue demonstrate, there is a clear conceptual compatibility between a sociomaterial interest in the broad range of actors that shape educational spaces and practices, and the postdigital recognition of the interconnectedness of the digital, material, biological and social.

The influence of digital technologies that is recognised through sociomaterial and postdigital perspectives also has the effect of blurring the boundary between the physical classroom and the online environments where learning happens. Although there is a certain convenience, and perhaps an administrative necessity, in distinguishing between degree programmes that are delivered either 'on campus' or 'online', it is a distinction that ignores the postdigital reality of contemporary learning. Following Goodyear's (2021) suggestion, we may seek to reflect on the complexity of the classroom through ethnographic observation, for instance in the typical university lecture theatre. Arriving early and securing a seat at the back of the auditorium, we would watch students arrive, before opening their laptops and logging into the university's learning management system. From there they might download the slides for that session or access the network drive where they compose and collect their class notes. As the lecture unfolds, the mention of an unfamiliar term would likely see students seeking clarification via Wikipedia or an equivalent site, and perhaps also checking their understanding with fellow students via the class WhatsApp group.

In these moments the student is physically situated in the classroom but is at the same time actively present within and beyond the University's online estate, as argued by Lamb (2019) in his own ethnographic study of higher education learning spaces. Within the postdigital university, digital technologies are woven into our everyday educational surroundings (Feenberg 2019; Jandrić et al. 2018), evidenced in the above example through the laptop computer, learning management system, networked drive, smartphone, social media app and internet connection. We therefore see physical and online learning environments as connected and co-determining, albeit contingent on a wider entanglement of actors and infra-structure.

The ubiquity of digital technologies across education and society has led to new ways of thinking about learning environments, thereby blurring the boundaries between 'formal' and 'informal' space, and being either 'online' or 'on campus' (Carvalho et al. 2016; Gourlay and Oliver 2016). Most recently, the term 'hybridity' has become firmly established within the higher education lexicon as educators and universities have sought to navigate and advertise a response to the imposed conditions of Covid-19.

Pushed by the spatial and strategic uncertainties of the pandemic, educators and universities have more readily recognised the particularities and potentialities of learning that happens across physical and online spaces (Boys 2021), which includes a broader range of permutations for teaching and learning (Wilson 2021). As Raes (2021) helpfully reminds us, however, pedagogy that is designed to take place both 
on-site and online pre-dates by some years the popular usage of 'hybridity' during pandemic times. For instance, the notion of hybridity is deployed in the learning spaces literature by Nordquist and Lang (2015) and by Boys (2016) to recognise the convergence of physical and virtual learning environments, prior to the point that campuses became inaccessible through Covid-lockdown. The imbricating nature of physical and online space learning is neatly captured in the concept of the 'hybrid lecture theatre', which Raes (2021) uses to investigate student presence and engagement within her own university.

Hybridity is also explored in our Special Issue by Pischetola (2021), this time in the context of professional development among higher education teachers in Denmark. Pischetola reports on the early findings of a study that aims to generate imaginative pedagogies that tap into the potentialities of digital technologies, while at the same time nurturing ontological aspects of the teaching profession. In the dynamic world of postdigital higher education, Pischetola argues, environments that encourage 'knowing-in-practice' over the acquisition of knowledge, create room for imagination in teaching with technologies.

This and other studies within this Special Issue recognise the spatial and pedagogical opportunities that have accompanied the rise to prominence of hybridity with the postdigital university. At the same time, Green (2021) and Wilson (2021) are among those who acknowledge the complications and challenges that come with designing teaching that transcends a single delivery mode. There is a need, Green (2021) argues, for targeted support to enable teachers to tap into the rich potential of hybrid learning, while Wilson (2021) suggests that a solution to navigating the wide range of pedagogical and permutations of hybridity might be found through the representation of musical forms.

It is clear, then, that the concept of postdigital learning space, and its relationship with digital technologies, can be approached in a range of ways. However, rather than seeing a contradiction in these different conceptualisations, on the contrary we suggest that during a period of considerable societal and technological change, it is helpful to be able to interpret and interrogate learning spaces and practices in different ways. Theoretical interrogations of space provide us with 'ways of thinking' about the complexity of educational environments and activities, while more context-driven studies generate the practicable knowledge that can influence how we seek to configure our learning spaces and practices. This mixture of theoretical with more practical approaches (and a number of the articles productively combine the two), enables this Special Issue to go beyond what Goodyear et al. (2018) have criticised as a tendency for academics to add nuance to existing interpretations, rather than offering actionable knowledge that might meaningfully inform the design of learning spaces in a more concrete (or networked) way.

\section{Exploring Space}

Beyond the different ways of conceptualising space, the work brought together within this Special Issue also demonstrates that educational environments and practices can be explored through a range of methods. In the pursuit of a nuanced 
understanding of the ways that digital technologies might extend undergraduate experiences across and beyond the physical classroom, Jenny Green (2021) discusses interviews with teacher-designers as part of a multiple case study approach in professional health education in Aotearoa New Zealand. Her focus on a practicebased method, which draws on contemporary ecological perspectives in education, enables Green (2021) to make the case that staff might become better able to exploit the potential of hybrid learning environments through targeted support, enabling them to recognise what is distinct about these emerging learning environments.

More specifically, this could involve the provision of personal development opportunities, including work on authentic assessment tasks, structured opportunities for dialogue between staff as they adapt to these new pedagogical and spatial surroundings, and a personal teaching toolkit specifically tailored for hybrid environments. The conversations Green (2021) held with academic staff valuably surface how shifting formations of space and technology require universities to devise new ways of supporting staff in order to maintain high-quality teaching and learning during a period of change.

Learning space is also experienced and understood through its aural qualities, even if few studies to date have examined higher educational environments through sonic methods or material. The case for tuning a critical ear to our educational surroundings has previously been made by Ceraso (2018) in her work around multimodality and embodied listening, while Gallagher et al. (2016) explored how online distance students used sound as way of actively negotiating personalised learning spaces away from the university campus. In this Special Issue we are glad to offer two original contributions that draw upon, but also extend beyond, these and other existing pieces of scholarship on the subject.

Using the device of the 'soundscape' - that is, the sonic characteristics of a specific setting - Ahern (2021) asks how we might nurture positive online learning environments through the 'planting' of non-verbal sounds. In a way that helpfully reminds us that digital technologies increasingly enable learners to actively shape their own educational surroundings (Gallagher et al. 2016), Ahern (2021) considers how the online synchronous sessions that have become standard practice during the Covid-19 pandemic might be enhanced by enabling students to contribute sounds towards these environments. The role of the teacher, Ahern proposes, might also broaden to include that of the curator and a designer of sonic material.

If we accept that teaching and learning are in some way contingent upon the ambient sounds that accompany the performance of these activities (and it would be hard, we suggest, to find an educator who would argue otherwise), and that digital platforms are a ubiquitous component of the postdigital university, there is a persuasive case for considering whether and how we might use sonic material to nurture positive online learning environments. The practical suggestions offered here by Ahern (2021) begin a conversation on how this might be realised.

Wilson (2021) uses sound in a different way, instead proposing that we might confront the challenge of designing hybrid learning spaces by looking towards diagrammatic representations of the spatial and temporal dimensions of music. As it becomes increasingly difficult to neatly separate physical and networked learning environments, and where members of a single class are co-located, there is need for 
original approaches to learning design. We might draw inspiration, Wilson (2021) argues, by looking towards music theory, and potential parallels between temporal and spatial representations of musical forms, and the sequencing and interaction of different components within learning design. Wilson hereby advances a new method for critically investigating postdigital learning space, which takes a musically informed approach to visually representing and exploring technologically affected educational environments.

Visual material also plays an important role in the examination of learning spaces and practices provided by Wardak et al. (2021). With an interest in understanding student experiences of lockdown during the Covid-19 pandemic, students within an Australian university business school were invited to compose short stories and social media artefacts around the hashtag '\#OurPlace2020'. The images, videos and other material that were generated, and analysed through the authors' use of Actor Network Theory and the Foucauldian concept of Heterotopia (1996), provide fascinating insights into where students were studying during lockdown, but also their uncertainty and strategizing as they sought to negotiate learning beyond the lecture hall and seminar room.

In common with the way that Lamb and Ross (2021) used Twitter conversation around lecture capture technologies to examine the shifting spatiality and temporality of higher education, Wardak et al. (2021) demonstrate the value and validity of looking towards social media to understand educational environment and practices. Through the creation of a research design that moves beyond conventional approaches and instead synchronises with the specific learning context, they deploy what we see as a speculative method (Michael 2016; Ross 2017). In a postdigital world where social media has become woven through the everyday practices and surroundings of students, it seems likely that the kind of method described by Wardak et al. (2021) will become commonplace as a way of opening-up the complexity of contemporary learning spaces and practices.

The work introduced above is consistent with the greater body of learning spaces research in using qualitative methods to interrogate the complexity of educational environments and practices. Raes (2021), however, combines qualitative and quantitative methods within a case study approach as part of a larger project taking place in her own university in Belgium. With an interest in investigating engagement and presence in two emergent learning environments, and a wish to capture the experiences both of students and staff, Raes analyses surveys as well as semi-structured interviews. Drawing across these data, Raes (2021) reiterates the conclusions drawn by other authors within this Special Issue, that the design of hybrid spaces and teaching demands careful consideration to the pedagogical, the social and the technological.

\section{Space, Technology and the Covid-19 Pandemic}

At the point of writing this Editorial, two years after the emergence of Covid-19, educators and universities continue to wrestle with the challenges and uncertainties it has provoked. Against this backdrop of uncertainty, it is understandable that Raes 
(2021) and many of the other contributors to this Special Issue have explored learning space, and its relationship with digital technology, in relation to the pandemic. We have already noted how the onset of the pandemic provoked new ways of conceptualising space, a foregrounding of digital technologies, a rise to prominence of hybridity, and a rapid migration towards networked platforms that enabled higher education to continue functioning while students and staff were physically distant from the classroom and campus.

For Wilson (2021), the rush to get online has made it even more important for universities to develop a visual language to support the implementation of new teaching and learning structures that responds to an evolving educational landscape. Boys (2021) similarly acknowledges the urgency for universities to react to the imposed conditions of lockdown, but also recognises it as a 'breach' moment, where educators paused to appreciate problems within some of the accepted assumptions around teaching and learning, and to consider alternative approaches going forward. This includes the emergence of large communities of educators who came together amid the pandemic to explore different kinds of learning spaces and practices.

These experiences, according to Pischetola (2021), will surely have impacted on teachers' professional identities, as well as their everyday practices. The willingness of teachers to embrace new spatial and pedagogical formations during Covid-19, while at the same time exploring how to further exploit the potentialities of digital resources, echoes Goodyear's (2021) view of pandemic experiences having punctured the notion that teachers are reluctant to change and resistant to technology.

It was inevitable and important that the impact of Covid-19 should be explored within the Special Issue; however, this does not anchor the different arguments to a particular period in the life of the university. Without denying the considerable disruption of the pandemic, a number of the articles presented here, including those by Boys (2021) and Raes (2021), discourage us from seeing the pandemic as having provoked a clean spatial and pedagogical break from the past. The necessity of teaching online undoubtedly meant that many students and teachers experienced university space in new ways; however, fully online programmes have for some time been a feature of higher education, while the academic database, search engine and learning management system are firmly established components of university learning. The pandemic brought new prominence to digital platforms and pedagogies; however, the technologically affected reconceptualization and reconfiguration of learning space needs to be recognised as part of a postdigital trajectory that precedes, but will also transcend, the inaccessibility of the physical classroom.

Across an extended period of being physically distant from the campus, students and teachers have experienced and negotiated new spatial arrangements and practices. Some of these environments and experiences will have been uncomfortable and unproductive; however, there will also have been moments and modes of engagement that transformed our perception of learning, of space, and of the university itself. We continue to encounter educators and institutions talking with apparent confidence about a post-Covid 'return to normal'. However, we find the possibility of winding the clock back to pre-pandemic assumptions about pedagogy and space to be unrealistic. To accept this possibility would assume we have been left unchanged by what has happened across an unprecedented period of disruption. 
More generally, fluctuating infection rates and new virus strains leave us far from certain that Covid disruption will, indeed, soon be over. Instead, and as the work across this Special Issue demonstrates, lockdown suggested new ways of conceptualising and configuring space, enabled by the potentialities of digital technologies.

\section{Building a Positive Postdigital University}

For all that Covid-19 provoked anxiety, disruption and uncertainty within higher education, it has at the same time provided an opportunity to reflect upon the kind of university we desire. As Boys (2021) notes in her discussion of inequalities within learning spaces and practices, although the pandemic has been widely framed in terms of a massive shift from regular in-person teaching to the abnormality of online education, we might instead consider how its impact has perpetuated but also disrupted pre-existing assumptions of university education. Starting from the position that higher education exists as an evolving entanglement of social, spatial and material practices, and drawing on work within disability and education studies, Boys (2021) argues for a more nuanced way of recognising what counts as evidence of learning within virtual and physical environments.

This includes rethinking existing curricula and modes of engagement in order to better recognise the life experiences of students who are ignored or invisible within existing structures and stereotypes. Therefore, alongside the challenges that Covid$19 \mathrm{had}$ presented to educators and universities, there has also been an opportunity to reflect on what matters within teaching and learning, and the chance to consider how we might want to rethink our learning spaces going forward.

This emphasis on positively imagining learning spaces and practices is also taken up by Peter Goodyear (2021) as he explores how we might realise the kind of university we desire, by pursuing questions around design justice, educational infrastructure and social innovation. Looking towards Raewyn Connell's (2019) account of the good university, Goodyear (2021) calls for clearer language and stronger concepts to support learning spaces and practices, in addition to infusing the curriculum with approaches from the fields of social innovation and participatory design in order to orient students to the challenges they will confront in the coming decades. Among other ways, we might begin to realise these ambitions, Goodyear (2021) suggests, through the creation of design studios that look towards the sociomaterial infrastructures and practices associated with collaborative design of new services. We might also seek to recognise sites beyond the campus where social innovation is already happening, while at the same time making the boundaries of the university more permeable, in order to forge links with communities and individuals who would otherwise be anxious or wary of engaging with higher education.

The desire for a better university that Boys (2021) and Goodyear (2021) pursue is, in fact, a thread that runs across this Special Issue, mostly through an exploration of the ways that digital technologies might nurture the kinds of learning spaces and conditions that we wish to characterise the postdigital university. We are careful, though, to avoid suggesting that digital technologies represent a panacea for the challenges experienced with higher education, or that they can be instrumentally deployed to neatly 
realise outcomes around accessibility, equality, learning design and beyond. On the contrary, technologies can and do work against these same conditions that we might desire within our university spaces, whether by enabling surveillance (see for instance Prinsloo and Slade 2016), extending educational inequality (Czerniewicz et al. 2020), or engendering a culture of distrust among staff and students (Bayne et al. 2020).

We need to remember that, from a postdigital perspective, the influence of technology is relational to other biological, material and social constraints, opportunities and resources. Nevertheless, as Boys (2021) and Goodyear (2021) argue here, we should recognise and pursue the possibility of configuring technology, pedagogy and space in ways that promote the kind of postdigital university we desire.

\section{The Postdigital Learning Spaces of Higher Education}

What can we say, then, about the relationship between digital technologies and learning spaces within the postdigital university? To begin, the different articles across this Special Issue highlight the importance of thinking critically and conceptually about the idea of learning space, and that this can be achieved in different but nevertheless, compatible ways. We can productively explore space by examining the relationship between physical and digital learning environments, focusing on pedagogy and learning design, as well as engaging more philosophically and critically with the established ideas in these areas.

The different articles collected here also make clear that the complex relationship between technologies and learning spaces might be interrogated through a range of methods. We can make sense of our educational surroundings through case studies and interview conversation, through sonic methods and social media, and via images and interviews, as well as other approaches. These methods might be conceptually underpinned in a range of ways, although we have seen that a sociomaterial sensibility is particularly suited to investigating the spatial, technological and pedagogical arrangements of the postdigital university.

This Special Issue comes at a crucial time as we seek to understand how digital technologies are transforming how we conceptualise and construct spaces for learning. The authors have taken up this challenge by asking questions and advancing ideas concerned with accessibility and equality, presence and engagement, pedagogical practice and, even more fundamentally, what we want the university to be. Brought together, their work enables us to better understand the relationship between digital technologies and educational environments and practices, and in so doing have given us a great deal to work with as we seek to critique and craft the postdigital learning spaces of higher education.

\section{References}

Ahern, K. F. (2021). Soundscaping Learning Spaces: Online Synchronicity and Composing Multiple Sonic Worlds. Postdigital Science and Education. https://doi.org/10.1007/s42438-021-00261-5.

Bayne, S., Evans, P., Ewins, R., Knox, J., Lamb, J., Mcleod, H., et al. (2020). The Manifesto for Teaching Online. Cambridge, MA: MIT Press. 
Bayne, S., Gallagher, M. S., \& Lamb, J. (2013). Being 'at' university: the social topologies of distance students. Higher Education, 67(5), 569-583. https://doi.org/10.1007/s10734-013-9662-4.

Bourdieu, P. (1977). Outline of a theory of practice. Trans. R. Nice. Cambridge: Cambridge University Press.

Boys, J. (2011). Towards Creative Learning Spaces: Re-Thinking The Architecture of Post- Compulsory Education. London and New York: Routledge.

Boys, J. (2016). Finding the Spaces In-Between: Learning as a Social Material Practice. In L. Carvalho, P. Goodyear, \& M. de Laat (Eds.), Place-based spaces for networked learning (pp. 59-72). New York: Routledge.

Boys, J. (2021). Exploring Inequalities in the Social, Spatial and Material Practices of Teaching and Learning in Pandemic Times. Postdigital Science and Education. https://doi.org/10.1007/s42438-021-00267-z.

Carvalho, L., Goodyear, P., \& de Laat, M. (2016). Place, Space, and Networked Learning. In Carvalho, L., Goodyear, P., \& de Laat, M. (Eds.) Place-based spaces for networked learning (pp. 1-10). New York: Routledge.

Ceraso, S. (2018). Sounding Composition: Multimodal Pedagogies for Embodied Listening. Pittsburgh, PA: University of Pittsburgh Press.

Connell, R. (2019). The good university: what universities actually do and why it's time for radical change. Clayton, VIC: Monash University Publishing.

Coulson, J., Roberts, P. \& Taylor, I. (2015). University Trends: Contemporary Campus Design. 2nd Edition. Abingdon and New York: Routledge.

Czerniewicz, L., Agherdien, N., Badenhorst, J. et al. (2020). A Wake-Up Call: Equity, Inequality and Covid-19 Emergency Remote Teaching and Learning. Postdigital Science and Education, 2(3), 946-967. https://doi.org/10.1007/s42438-020-00187-4.

Feenberg, A. (2019). Postdigital or predigital? Postdigital Science and Education, 1(1), 8-9. https://doi. org/10.1007/s42438-018-0027-2.

Foucault, M. (1996). Rituals of exclusion. Trans. J. Johnston. In S. Lotringer (Ed.), Foucault Live: Interviews, 1961-84 (pp. 68-73). New York: Semiotext(e).

Gallagher, M. S., Lamb, J., \& Bayne, S. (2016). The Sonic Spaces of Online Distance Learners. In L. Carvalho, P. Goodyear, \& M. de Laat (Eds.), Place-based spaces for networked learning (pp. 87-99). New York: Routledge.

Goodyear, P. (2021). Realising the Good University: Social Innovation, Care, Design Justice and Educational Infrastructure. Postdigital Science and Education. https://doi.org/10.1007/ s42438-021-00253-5.

Goodyear, P., Ellis, R. A., \& Marmot, A. (2018). Learning Spaces Research: Framing Actionable Knowledge. In R. A. Ellis \& P. Goodyear (Eds.), Spaces of Teaching and Learning: Integrating Perspectives on Research and Practice (pp. 221-230). Singapore: Springer. https://doi.org/10.1007/978-981-107155-3_12.

Gourlay, L. (2021). Presence, Absence, and Alterity: Fire Space and Goffman's Selves in Postdigital Education. Postdigital Science and Education. https://doi.org/10.1007/s42438-021-00265-1.

Gourlay, L., \& Oliver, M. (2016). Students' Physical and Digital Sites of Study: Making, Marking and Breaking Boundaries. In L. Carvalho, P. Goodyear, \& M. de Laat (Eds.), Place- based spaces for networked learning (pp. 73-86). New York: Routledge.

Gourlay, L., \& Oliver, M. (2018). Student engagement in the digital university: Sociomaterial assemblages. Abingdon: Routledge.

Green, J. K. (2021). Designing Hybrid Spaces for Learning in Higher Education Health Contexts. Postdigital Science and Education. https://doi.org/10.1007/s42438-021-00268-y.

Hodges, C., Moore, S., Lockee, B., Trust, T., \& Bond, A. (2020). The difference between emergency remote teaching and online learning. Educause Review, 27 March. https://er.educause.edu/articles/2020/3/thedifference-between-emergency-remote-teaching-and-online-learning. Accessed 23 November 2021.

Jandrić, P., Hayes, D., Truelove, I., Levinson, P., Mayo, P., Ryberg, T., Monzó, L.D., Allen, Q., Stewart, P.A., Carr, P.R., Jackson, L., Bridges, S., Escaño, C., Grauslund, D., Mañero, J., Lukoko, H.O., Bryant, P., Fuentes Martinez, A., Gibbons, A., Sturm, S., Rose, J., Chuma, M.M., Biličić, E., Pfohl, S., Gustafsson, U., Arantes, J.A., Ford, D.R., Kihwele, J.E., Mozelius, P., Suoranta, J., Jurjević, L., Jurčević, M., Steketee, A., Irwin, J., White, E.J., Davidsen, J., Jaldemark, J., Abegglen, S., Burns, T., Sinfield, S., Kirylo, J.D., Batarelo Kokić, I., Stewart, G.T., Rikowski, G., Lisberg Christensen, L., Arndt, S., Pyyhtinen, O., Reitz, C., Lodahl, M., Humble, N., Buchanan, R., Forster, D.J., Kishore, P., Ozoliņ̌s, J., Sharma, N., Urvashi, S., Nejad, H.G., Hood, N., Tesar, M., Wang, Y., Wright, J., Brown, J.B., Prinsloo, P., Kaur, K., Mukherjee, M., Novak, R., Shukla, R., Hollings, S., Konnerup, 
U., Mallya, M., Olorundare, A., Achieng-Evensen, C., Philip, A.P., Hazzan, M.K., Stockbridge, K., Komolafe, B.F., Bolanle, O.F., Hogan, M., Redder, B., Sattarzadeh, S.D., Jopling, M., SooHoo, S., Devine, N., \& Hayes, S. (2020). Teaching in The Age of Covid-19. Postdigital Science and Education, 2(3), 1069-1230. https://doi.org/10.1007/s42438-020-00169-6.

Jandrić, P., Knox, J., Besley, T., Ryberg, T., Suoranta, J., \& Hayes, S. (2018). Postdigital Science and Education. Educational Philosophy and Theory, 50(10), 893-899. https://doi.org/10.1080/00131 857.2018.1454000.

Lamb, J. (2019). Space, Sociomateriality, Sound: The Learning Spaces of Higher Education. Doctoral dissertation. Edinburgh: University of Edinburgh.

Lamb, J., \& Ross, J. (2021). Lecture capture, social topology, and the spatial and temporal arrangements of UK universities. European Educational Research Journal. https://doi.org/10.1177/1474904121993982.

Latour, B. (2005). Reassembling the Social: An introduction to Actor-Network Theory. Oxford: Oxford University Press.

Law, J., \& Mol, A. (2001). Situating technoscience: an enquiry into spatialities. Environment and Planning D, 19(5), 609-621. https://doi.org/10.1068/d243t.

Lefebvre, H. (1991). The Production of Space. Trans. D. Nicholson-Smith. Oxford: Blackwell.

Massey, D. (2005). For space. London: SAGE.

Michael, M. (2016). Notes toward a speculative methodology of everyday life. Qualitative Research, 16(6), 646-660. https://doi.org/10.1177/1468794115626245.

Nordquist, J., \& Laing, A. (2015). Designing spaces for the networked learning landscape. Medical Teacher, 37(4), 337-343.https://doi.org/10.3109/0142159X.2014.1001349.

Pischetola, M. (2021). Teaching Novice Teachers to Enhance Learning in the Hybrid University. Postdigital Science and Education. https://doi.org/10.1007/s42438-021-00257-1.

Prinsloo, P., \& Slade, S. (2016). Student vulnerability, agency, and learning analytics: An exploration. Journal of Learning Analytics, 3(1), 159-182. https://doi.org/10.18608/jla.2016.31.10.

Raes, A. (2021). Exploring Student and Teacher Experiences in Hybrid Learning Environments: Does Presence Matter?. Postdigital Science and Education. https://doi.org/10.1007/s42438-021-00274-0.

Rapanta, C., Botturi, L., Goodyear, P., Guardia, L., \& Koole, M. (2021). Balancing Technology, Pedagogy and the New Normal: Post-pandemic Challenges for Higher Education. Postdigital Science and Education. 3(3), 715-742. https://doi.org/10.1007/s42438-021-00249-1.

Ross, J. (2017). Speculative method in digital education research. Learning, Media and Technology, 42(2), 214-229. https://doi.org/10.1080/17439884.2016.1160927.

Wardak, D., Vallis, C., \& Bryant, P. (2021). \#OurPlace2020: Blurring Boundaries of Learning Spaces. Postdigital Science and Education. https://doi.org/10.1007/s42438-021-00264-2.

Wilson, S. A. (2021). Musical Lens on Spatial Representations of Form to Support Designers and Teachers Using Hybrid Learning Spaces. Postdigital Science and Education. https://doi.org/10.1007/ s42438-021-00262-4.

Publisher's Note Springer Nature remains neutral with regard to jurisdictional claims in published maps and institutional affiliations. 